\title{
Effect of Alkaline Activator on the Strength of Titanium- Gypsum Based Cementitious Materials
}

\author{
Chaoyu Li \\ School of \\ Transportation and \\ Vehicle Engineering \\ Shandong \\ University of \\ Technology \\ Zibo, China
}

\author{
Liangjun Xv \\ Shandong Luzhong \\ Highway \\ Construction Co., \\ Ltd \\ Zibo, China
}

\author{
Zhirong Jia* \\ School of Civil and \\ Architecture \\ Engineering \\ Shandong \\ University of \\ Technology \\ Zibo, China \\ Corresponding
}

\author{
Zhen Lei \\ School of \\ Transportation and \\ Vehicle Engineering \\ Shandong \\ University of \\ Technology \\ Zibo, China
}

\author{
Xuefeng Lin \\ School of \\ Transportation and \\ Vehicle Engineering \\ Shandong \\ University of \\ Technology \\ Zibo, China
}

\begin{abstract}
In order to determine the type of alkaline activator for gypsum-based slag cementitious materials, the fixed mass ratio of titanium slag and gypsum to 9: 1 , and $\mathrm{Na}_{2} \mathrm{SiO}_{3}$, triethanolamine, $\mathrm{Na}_{2} \mathrm{SiO}_{3}$ mixed with triethanolamine were used to three activators. Then, nine groups of gypsum-based slag cementitious material test pieces were made with the dosage of alkaline activator $0.6 \%, 1 \%$, and $1.2 \%$, and the unconfined compressive strength was performed for 7 days. The experimental results showed that triethanolamine should not be used alone as an activator, the effect of compound $\mathrm{Na}_{2} \mathrm{SiO}_{3}$ and triethanolamine is better than that of $\mathrm{Na}_{2} \mathrm{SiO}_{3}$ used alone, and the 7-day unconfined compressive strength of the cementing material is higher than 1.5Mpa.
\end{abstract}

Keywords: Cementitious materials, Titanium-gypsum, Alkali excitation, Compressive strength

\section{INTRODUCTION}

Titanium gypsum is an industrial by-product produced during the production of titanium dioxide by the sulfuric acid method. It is mainly produced by adding lime to neutralize acidic wastewater generated in the production process, and produces solid waste mainly composed of dihydrate gypsum. When it just came out of the treatment workshop, it was graybrown, and $\mathrm{Fe}^{2+}$ in the air was gradually oxidized to $\mathrm{Fe}^{3+}$ and turned red, so it was also called red gypsum. In China, the general production of $1 \mathrm{t}$ sulphuric acid titanium dioxide will produce $6 \sim 10 \mathrm{t}$ of titanium gypsum. At present, the annual production of titanium-gypsum is about 10 million in China, but its utilization rate is very low, most of which adopt the way of open dumping [1].

In the preparation of cementitious materials by industrial waste gypsum, some experts and scholars have done a lot of research, which is of referential significance to the preparation of titanium-gypsum based slag cementitious materials. Hyeoneun Park[2] added 10\% gypsum to lime activated slag (slag: lime: gypsum $=85: 5: 10$ ) can have the best mechanical properties, and the compressive strength can reach $30 \mathrm{Mpa}$ and 40Mpa in 7 and 28 days. M.S. Morsy [3] through the fixed ratio of metakaolin-fly ash-lime (40:30:30), with different content of anhydrite $(0 \%, 2.5 \%, 5 \%, 7.5 \%, 10 \%)$ test, found that the compressive strength is not the same age period is along with the increase with the increase of the content of anhydrite, its compressive strength is within 7 days of growth is slower, but in the later as the growth of the curing age. Sun jiaying [4] added titanium-gypsum with an admixture of less than $4 \%$ into the lime-fly ash stabilized material, and found that the early strength of the mixture was improved, with no negative effect on the later strength. Jiangwei Li [5] found that the 7-day unconfined compressive strength of clinker-fly ash-gypsum(45:45:10) stabilized gravel pavement base material was higher than that of P.S 32.5 cement, and the strength was nearly $10 \%$ higher than that of P.S32.5 cement. Zhao deqiang [6] prepared pavement base cementite by using $40 \%$ clinker, $35 \%$ fly ash, $15 \%$ phosphogypsum and $10 \%$ steel slag as the optimal mix ratio, and its strength was $20 \%$ $50 \%$ higher than that of the compacted material stabilized by two-ash broken gravel.

Based on the above research status, the use of alkaline activators for gypsum based cementing materials is mostly based on cement clinker or lime, which will not only aggravate the exploitation of natural resources such as limestone, but also cause environmental damage. So, If can reduce economic cost, reduce the use of lime and other natural resources for the principle, in order to improve the utilization rate of titanium gypsum for the purpose, if the titaniumgypsum and slag materials are combined together through the appropriate alkaline activator, the strength of the cementitious materials can be effectively improved, and a low-cost and high-quality alkaline activator of gypsum based cementitious materials can be realized, which is of great significance for the preparation of titanium-gypsum based cementitious materials. In this paper, the effect of alkaline activator on the strength and properties of titanium-gypsum based slag cementitious materials was studied, and the optimal form of alkaline activator was determined.

\section{MATERIALS and METHODS}

\subsection{Raw Materials}

1) Titanium-gypsum: It was taken from the industrial waste generated by a chemical enterprise in Zibo, Shandong. The 
main component is $\mathrm{CaSO}_{4} \cdot 2 \mathrm{H}_{2} \mathrm{O}$, and the content is generally $60 \% \sim 80 \%$. The other main chemical components are shown in Table1. The crystalline water and adsorbed water in titanium-gypsum exist at the same time. The titanium-gypsum was dried at $60^{\circ} \mathrm{C}$ to a constant weight and then turned pale yellow. After cooling, it was passed through a $2.43 \mathrm{~mm}$ square-hole sieve.

2) Slag: Obtained from a building materials enterprise in Hebei province, this is a light gray powdery solid with a density of $2.9 \mathrm{~g} / \mathrm{cm}^{3}$, a specific surface area of $418 \mathrm{~m}^{2} / \mathrm{kg}$, and a 28-day activity index of $97 \%$. Its main chemical composition are shown in Table 1.

Table 1. The chemical composition of titanium-gypsum and slag (mass fraction \%)

\begin{tabular}{|c|c|c|}
\hline Composition & $\begin{array}{c}\text { Titanium } \\
\text { gypsum }\end{array}$ & Slag \\
\hline $\mathbf{A I}_{2} \mathbf{O}_{3}$ & 1.82 & 13.5 \\
\hline $\mathbf{C a O}$ & 30.21 & 39.4 \\
\hline $\mathbf{M g O}$ & 1.92 & 7.5 \\
\hline $\mathbf{S O}_{3}$ & 37.06 & 2.28 \\
\hline $\mathrm{SiO}_{2}$ & 2.83 & 26.4 \\
\hline $\mathbf{T i O}_{2}$ & 3.84 & 1.31 \\
\hline $\mathbf{N a}_{2} \mathbf{O}$ & - & 0.423 \\
\hline $\mathrm{K}_{2} \mathbf{O}$ & - & 0.305 \\
\hline $\mathbf{M n O}^{\mathbf{F e}_{2} \mathbf{O}_{3}}$ & - & 0.384 \\
\hline
\end{tabular}

3) $\mathrm{Na}_{2} \mathrm{SiO}_{3}$ : Produced by Wuxi Yatai united chemical co., LTD., AR analysis pure, the molecular formula is $\mathrm{Na}_{2} \mathrm{SiO}_{3} \cdot 9 \mathrm{H}_{2} \mathrm{O}$, the molecular weight is 284.22 , white or gray white block or powder, easy to weathering, soluble in water, $\mathrm{Na}_{2} \mathrm{O}$ content is $19.3 \sim 22.8 \%, \mathrm{Na}_{2} \mathrm{O}$ and $\mathrm{SiO}_{2}$ mass ratio is 1:1.

4) Triethanolamine (TEA): Produced by Tianjin Dingsheng Xin chemical industry co., LTD., AR analysis pure, molecular formula is $\mathrm{C}_{6} \mathrm{H}_{15} \mathrm{NO}_{3}$, molecular weight is 149.1882 , colorless to light yellow viscous liquid, easy to absorb moisture, easy to dissolve in water.

\subsection{Experimental Methods}

In this experiment, first, the fixed mixing ratio of titanium gypsum and slag to 9: 1, followed by the addition of different contents of $\mathrm{Na}_{2} \mathrm{SiO}_{3}$, triethanolamine, compound $\mathrm{Na}_{2} \mathrm{SiO}_{3}$ and triethanolamine as three kinds of activator, made 9 sets of cementitious material test pieces, the mixing ratio is shown in Table2. The activators used in this paper were dissolved in water and mixed into titanium-gypsum. According to the optimal water content of titanium-gypsum, the water consumption of less than two percentage points was taken as the optimal water content of all the proportions, and then experiment after mixing and sealing for 12 hours. The specific experiment methods is as follows:

1) Proctor compaction test: According to JTG E40-2007[7], this experiment adopts light compaction test I-1, the determination of the maximum dry density and optimum water content of titanium gypsum. The moisture content of $20 \%, 22 \%, 24 \%, 26 \%, 28 \%, 30 \%$ and $32 \%$ were selected for proctor compaction test, and the results are shown in figure 1 . It can be seen from the test results that the optimal water content of titanium-gypsum is around $26 \%$, and its maximum dry density is $1.394 \mathrm{~g} / \mathrm{cm}^{3}$. When the water content is within the range of $24 \sim 28 \%$, the density changes little, both within the maximum dry density $\pm 0.02 \mathrm{~g} / \mathrm{cm}^{3}$.

2) 7-day unconfined compressive strength test: According to JTG E51-2009[8], the standard $\varphi 50 \mathrm{~mm} \times \mathrm{H} 50 \mathrm{~mm}$ specimen was prepared by static pressing with universal press, and the specimen was put into the standard curing box $\left(20^{\circ} \mathrm{C} \pm 2^{\circ} \mathrm{C}\right.$, relative humidity $\geq 95 \%$ ) for curing to the required age. On the last day of the curing period, the specimen was taken out and placed in $20^{\circ} \mathrm{C} \pm 2{ }^{\circ} \mathrm{C}$ water. The water surface was about $2.5 \mathrm{~cm}$ on the top of the specimen. After soaking for $24 \mathrm{~h}$, the water on the surface of the specimen was absorbed with a soft cloth. No less than 6 parallel samples were set for each group of experiments, and their representative values were taken for analysis.

Table 2. The mix proportions of specimen(mass fraction $\%)$

\begin{tabular}{|c|c|c|c|c|}
\hline $\begin{array}{c}\text { Grou } \\
\mathbf{p}\end{array}$ & $\begin{array}{c}\text { titanium } \\
\text { gypsum }\end{array}$ & slag & $\mathbf{N a}_{2} \mathrm{SiO}_{3}$ & $\begin{array}{c}\text { triethanolamin } \\
\mathbf{e}\end{array}$ \\
\hline $\mathbf{1}$ & 88 & 10.8 & 0.6 & 0.6 \\
\hline $\mathbf{2}$ & 90 & 9.4 & 0.4 & 0.2 \\
\hline $\mathbf{3}$ & 90 & 9.4 & 0.2 & 0.4 \\
\hline $\mathbf{4}$ & 88 & 10.8 & 1.2 & - \\
\hline $\mathbf{5}$ & 90 & 9 & 1 & - \\
\hline $\mathbf{6}$ & 90 & 9.4 & 0.6 & - \\
\hline $\mathbf{7}$ & 88 & 10.8 & - & 1.2 \\
\hline $\mathbf{8}$ & 90 & 9 & - & 0.6 \\
\hline $\mathbf{9}$ & 90 & 9.4 & - & \\
\hline
\end{tabular}

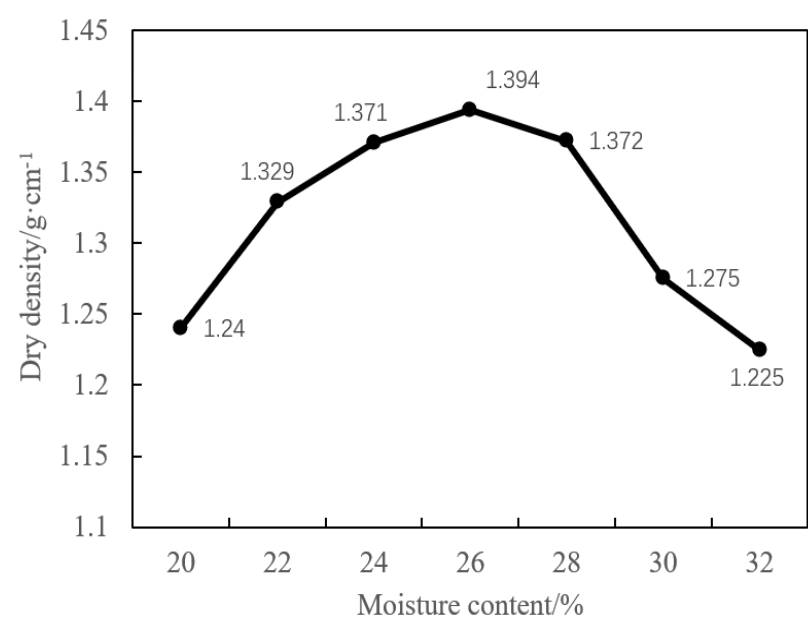

Figure 1. Dry density - moisture content curve of titanium-gypsum 


\section{RESULTS AND DISCUSSION}

\subsection{Effects of $\mathrm{Na}_{2} \mathrm{SiO}_{3}$ single activator on compressive strength of cementitious materials}

The effects of $\mathrm{Na}_{2} \mathrm{SiO}_{3}$ single activator on the compressive strength of cementitious materials are shown in Figure 2. It is to see that the strength of $\mathrm{Na}_{2} \mathrm{SiO}_{3}$ only as an alkaline activator can reach above $1.5 \mathrm{Mpa}$, in which the compressive strength reaches the maximum when the content of $\mathrm{Na}_{2} \mathrm{SiO}_{3}$ is $0.6 \%$, and the compressive strength is $2.2 \mathrm{Mpa}$. By comparing other mix ratios, it is found that when the $\mathrm{Na}_{2} \mathrm{SiO}_{3}$ content is $1.2 \%$, the compressive strength is only higher than $0.2 \mathrm{Mpa}$ with $1 \%$ content, with no significant difference between the two. This shows that the compressive strength are the best when the content of $\mathrm{Na}_{2} \mathrm{SiO}_{3}$ is $0.6 \%$, and the compressive strength in the early stage is obviously better than that of ordinary lime fly ash cementing materials.

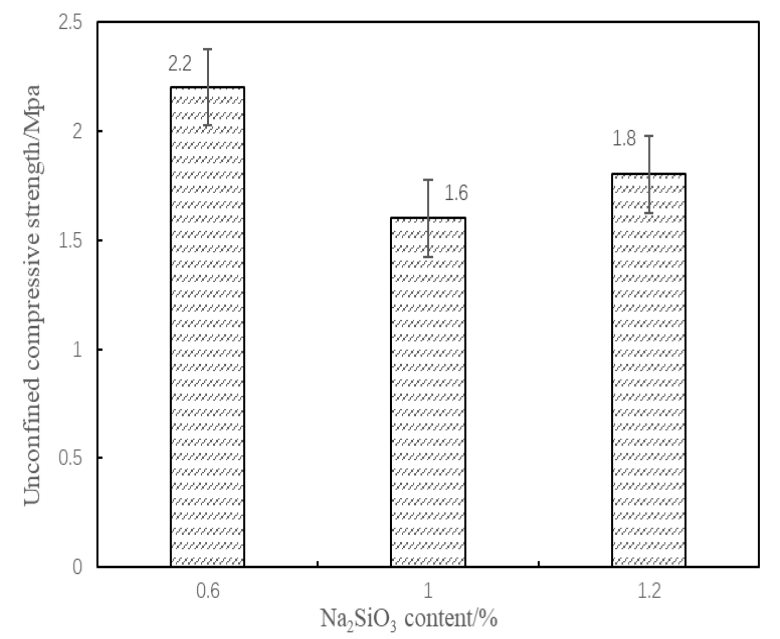

Figure 2. Effects of $\mathrm{Na}_{2} \mathrm{SiO}_{3}$ single activator on the compressive strength

This early strength was mainly due to the pozzolanic reaction between gypsum and slag[9]. Because there are a large number of $\mathrm{SO}_{3}$ and $\mathrm{CaO}$ compounds in titanium-gypsum, as well as a small amount of $\mathrm{SiO}_{2}, \mathrm{AI}_{2} \mathrm{O}_{3}$ and other active substances, this provides the basis for the early hydration reaction of the mixture. On the one hand, $\mathrm{Na}_{2} \mathrm{SiO}_{3}$ has a certain bond, which is because $\mathrm{Na}_{2} \mathrm{SiO}_{3}$ can exchange with $\mathrm{CO}_{2}$ and water to form a part of silica gel, which can realize the close connection of particles between the mixture and improve the strength of the mixture [10]. In addition, $\mathrm{Na}_{2} \mathrm{SiO}_{3}$ can also react with $\mathrm{CaSO}_{4} \cdot 2 \mathrm{H}_{2} \mathrm{O}$ to produce silica gel and sodium sulfate crystals, which can bond gypsum particles and make the structure more compact, which is conducive to improving the strength of stabilized titanium-gypsum mixture[11]. $\mathrm{Na}_{2} \mathrm{SiO}_{3}$, meanwhile, is able to provide hydration reaction of alkaline environment, can make the $\mathrm{Si}-\mathrm{O}$ keys inside the slag and AI-O keys vitreous body is broken by immediately, and quickly involved in the hydration reaction, can effectively generate hydrated calcium silicate (C-S-H), hydrated calcium aluminate (C-A-S-H) gel material, improve the compactness of mixture between, improve the strength, but in standard curing 7 days, the formation of these substances is weak [12]. On the other hand, the generation of early ettringite also provides the basis for the early strength, because $\mathrm{CaSO}_{4} \cdot 2 \mathrm{H}_{2} \mathrm{O}, \mathrm{SO}_{3}, \mathrm{CaO}$ and $\mathrm{AI}_{2} \mathrm{O}_{3}$ can produce calcium sulphoaluminate hydrate $(\mathrm{AFm})$, which is not yet fully developed to produce ettringite, and calcium sulphoaluminate hydrate $(\mathrm{AFt})$, which has initially developed into aciculus. In addition, the formation rate of ettringite is also related to the concentration and diffusion rate of $\mathrm{OH}^{-}$, $\mathrm{SO}_{4}{ }^{2-}$ and $\mathrm{Ca}^{2+}$ in the hydration environment. The diffusion of these ions to the solid-liquid interface formed by ettringite can lead to the continuous formation of ettringite [13]. These generated AFm and AFt crystals can fill the interstitial space in the mixture, making the mixture more compact, thus improving the early strength.

\subsection{Effects of triethanolamine single activator on compressive strength of cementitious materials}

When single triethanolamine (TEA) was used as an alkaline activator, the specimen was intact for 6 days before standard curing, and rapid disintegration occurred when it was soaked in water on the last day, in figure 3 . In the three mixing ratios of group 6, 7 and 8, disintegration occurred, which was quickly completed within half an hour after soaking in water. The most important part was gradual erosion from the root of the specimen, in figure 3a). After soaking for one day, some specimens completely disintegrated, in figure 3b). After complete disintegration, the specimen has a large particle size, sandy texture, and some viscous shape, in figure $3 \mathrm{c}$ ).

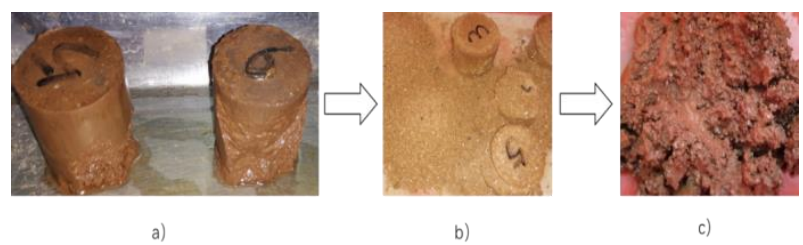

Figure 3. Disintegration of specimen only with triethanolamine a) Water immersion $0.5 \mathrm{~h}$; b) Water immersion for $24 \mathrm{~h}$; c) specimens after disintegration

Triethanolamine, as an organic matter, is also a good activator for slag. This is because the unshared electron pair on the $\mathrm{N}$ atom in its molecule is easy to form covalent bonds with $\mathrm{Ca}^{2+}$ in the liquid phase of the mixture, resulting in the complexation reaction to form the TEA- $\mathrm{Ca}^{2+}$ complex. However, the complex formed at this time is more soluble in water, and will form soluble zone points on the surface of the cementitious mineral particles, thus promoting the hydration reaction. Complex formed in the liquid phase, would result in higher hydration environmental $\mathrm{PH}$ value, promote the gelation of slag minerals $\left(\mathrm{C}_{2} \mathrm{~S} / \mathrm{C}_{3} \mathrm{~S}, \mathrm{Ca}(\mathrm{OH})_{2}\right.$, etc.) in the secondary hydration generated hydrated Tetracalcium aluminate $\left(\mathrm{C}_{4} \mathrm{AH}_{13}\right)$, inhibit the hydration tricalcium aluminate $\left(\mathrm{C}_{3} \mathrm{AH}_{6}\right)$ formation, can prevent the mixture in loose the production of crystal structure, improve the density and mechanical properties of hardened cement paste [14]. The rapid disintegration is mainly caused by the high content of triethanolamine and the short curing time, because 
triethanolamine has a strong alkalinity at a $\mathrm{PH}$ of 10.5 in an aqueous solution of $0.1 \mathrm{~mol} / \mathrm{L}$, and the content of triethanolamine in this experiment was $0.17 \sim 0.4 \mathrm{~mol} / \mathrm{L}$. In curing age, as a result of triethanolamine on the early hydration process of $\mathrm{C}_{3} \mathrm{~S}$ and $\mathrm{C}_{2} \mathrm{~S}$ has certain inhibition, and early generated TEA-Ca ${ }^{2+}$ complex soluble in water[14], and because of the early C-S-H gelling material such as the generation of a weak [12], the internal structure of the mixture was loose, and led to the complete disruption in the final $1 \mathrm{~d}$ of soak, so need to extend the curing age considering its hydration products late effect or to reduce the content of triethanolamine.

\subsection{Effects of $\mathrm{Na}_{2} \mathrm{SiO}_{3}$ mixed with triethanolamine activator on compressive strength of cementitious materials}

The effects of $\mathrm{Na}_{2} \mathrm{SiO}_{3}$ mixed with triethanolamine activator on the compressive strength of cementitious materials are shown in Figure 4. In the form of $\mathrm{Na}_{2} \mathrm{SiO}_{3}$ mixed with triethanolamine, when the mass ratio of $\mathrm{Na}_{2} \mathrm{SiO}_{3}$ to triethanolamine was $1: 1$, the compressive strength reaches the maximum, which is $3.1 \mathrm{Mpa}$. In by comparing with the dosage of $\mathrm{Na}_{2} \mathrm{SiO}_{3}$ and triethanolamine quality ratio of $2: 1$ and $1: 2$, $\mathrm{Na}_{2} \mathrm{SiO}_{3}$ content is higher than that of triethanolamine, the compressive strength is $2.4 \mathrm{Mpa}$, compressive strength is greater than the group 3, this means that when the dosage of $\mathrm{Na}_{2} \mathrm{SiO}_{3}$ content higher than that of triethanolamine, the role of excitation of the mixed agent in the mixture has a positive effect. Therefore, properly controlling the mass ratio of titanium gypsum to triethanolamine is beneficial to improve the strength of titanium gypsum-based slag cementitious material.

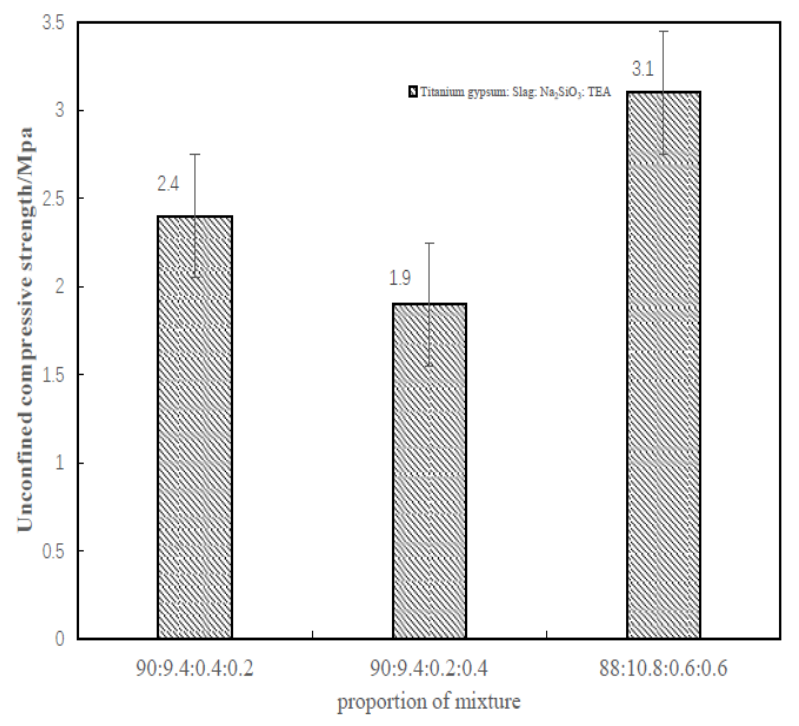

Figure 4. Effects of $\mathrm{Na}_{2} \mathrm{SiO}_{3}$ mixed with triethanolamine on compressive strength

Based on the comparison of $\mathrm{Na}_{2} \mathrm{SiO}_{3}$ single admixture and complex admixture forms, it can be seen from figure 5 that with the same amount of stimulant, the admixture strength of triethanolamine and $\mathrm{Na}_{2} \mathrm{SiO}_{3}$ is significantly higher than that of $\mathrm{Na}_{2} \mathrm{SiO}_{3}$ single admixture. When the mixture content of activator is $1.2 \%$, it is obviously better than the mix ratio of $\mathrm{Na}_{2} \mathrm{SiO}_{3}$ mixed form, and its compressive strength reaches 3.1Mpa, which is 1.5 times higher than that of $\mathrm{Na}_{2} \mathrm{SiO}_{3}$ mixed alone. When the co-admixture of activator was $0.6 \%$, the compressive strength of group 2 in the compound admixture was higher than $0.2 \mathrm{Mpa}$ for $\mathrm{Na}_{2} \mathrm{SiO}_{3}$. When the content of $\mathrm{Na}_{2} \mathrm{SiO}_{3}$ is $0.6 \%$, which is group 1 and group 6 , it can be found that the compressive strength of the compound mixture is higher than that of the single mixture. It can be concluded from the above, using compound $\mathrm{Na}_{2} \mathrm{SiO}_{3}$ and triethanolamine as the activator of cementitious materials in the early compressive strength is superior to the $\mathrm{Na}_{2} \mathrm{SiO}_{3}$ single activator.

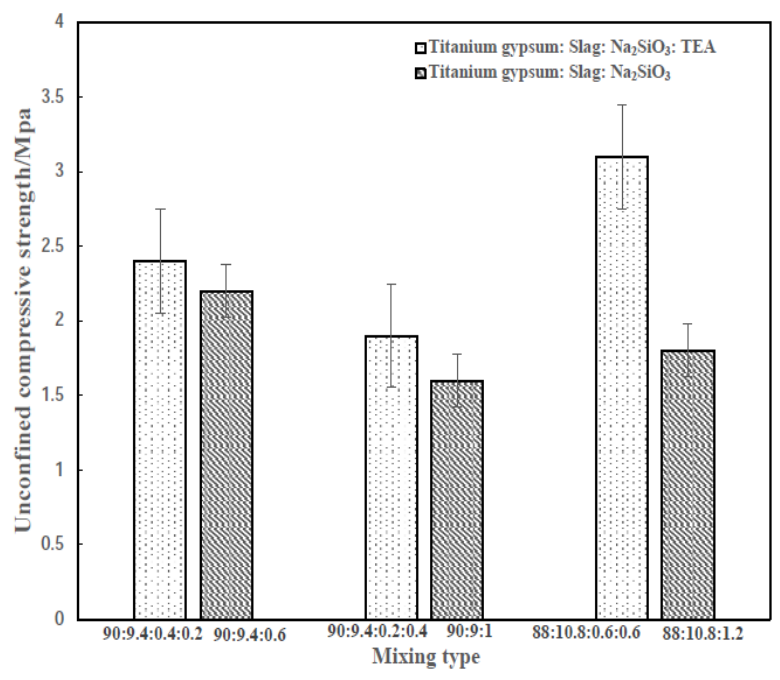

Figure 5. Comparison of compressive strength between compound admixture and single admixture

In terms of strength formation mechanism, this is mainly due to the fact that triethanolamine and $\mathrm{Na}_{2} \mathrm{SiO}_{3}$ can provide an alkaline environment for the hydration reaction in the mixture, then improve the $\mathrm{PH}$ value and promote the generation of hydration products. In addition, with the incorporation of triethanolamine(TEA), part of triethanolamine can also promote the solid for the TEA-Ca ${ }^{2+}$ complex formation $\mathrm{Ca}^{2+}$ from the dissolution of hydration products, accelerate the hydration reaction rate, and thus promote the sulfate, $\mathrm{Na}_{2} \mathrm{SiO}_{3}$ and $\mathrm{Ca}(\mathrm{OH})_{2}$ in hydration reaction, accelerate the gelling material (C-S-H) formation, but also can expand the gelling material (C-S-H) layer spacing, is advantageous to the induction of random aggregation $\mathrm{C}-\mathrm{S}-\mathrm{H}$ ordered arrangement and spongy structure formation, and TEA-Ca ${ }^{2+}$ complex formed many soluble in aqueous solution, The diffusion rate of hydration products is increased, secondary hydration of sulfate and $\mathrm{C}_{3} \mathrm{~A}$ is realized, and the generation of ettringite is accelerated, which is generated in large quantities in the early stage, so as to improve the compactness and compressive strength of the mixture[15]. At the same time, part of the hydrogen in the hydroxyl group of triethanolamine and $\mathrm{Na}_{2} \mathrm{SiO}_{3}$ form a composite crystal of silica gel $\left(\mathrm{mSiO}_{2} \cdot \mathrm{nH}_{2} \mathrm{O}\right)$ and triethanolamine sodium salt $\left(\mathrm{N}_{(}\left(\mathrm{C}_{2} \mathrm{H}_{4} \mathrm{ONa}\right)_{3}\right)$ composite crystal $\left(\mathrm{N}\left(\mathrm{C}_{2} \mathrm{H}_{4} \mathrm{ONa}\right)_{3} \cdot \mathrm{mSiO}_{2} \cdot \mathrm{nH}_{2} \mathrm{O}\right)$ [16]. The formation of 
these crystals can fill internal voids and improve their mechanical properties.

\section{CONCLUSION}

(1) When single $\mathrm{Na}_{2} \mathrm{SiO}_{3}$ was used as alkaline activator, the 7day compressive strength of titanium-gypsum based slag cementation materials is higher than $1.5 \mathrm{Mpa}$ when the dosage is $0.6 \%, 1 \%$ and $1.2 \%$. When the dosage is $0.6 \%$, the compressive strength is the highest among the three component ratios, reaching $2.2 \mathrm{Mpa}$.

\section{REFERENCES}

[1] Donglei Yang. 2018. Progress and prospect of resource utilization of phosphogypsum and titanium-gypsum in China [J]. Sulfuric acid industry, (10):5-10.

[2] Park H, Jeong Y, Jun Y, et al. 2016. Strength enhancement and pore-size refinement in clinker-free $\mathrm{CaO}$-activated GGBFS systems through substitution with gypsum[J]. Cement and Concrete Composites, S0958946516300208.

[3] Morsy M S, Alsayed S H, Salloum Y A. 2012. Development of eco-friendly binder using metakaolin-fly ash-lime-anhydrous gypsum[J]. Construction and Building Materials, 35:772-777.

[4] Sun J Y, Xu Y D. 2011. Study on the Effect of Waste Gypsum on Hardening Paste Structure and Performances of Lime-Fly Ash[J]. Advanced Materials Research, 213:31-34.

[5] Jiangwei Li,Weiguo Shen,et al. 2019. Investigation on the preparation and performance of clinker-fly ashgypsum road base course binder. Construction and Building Materials, 212:39-48.

[6] Deqiang Zhao, Bingliu Zhang, Shang Zhu, Duanxin Chen, Weiguo Shen. 2019. performance road base composite binder regulation [J] Journal of Building Materials, 1-10.

[7] Test Methods of Soil for Highway Engineering. JTG E40-2007, China Profession Standard.
(2) When single triethanolamine was used as alkaline activator, rapid disintegration occurs after $0.6 \%, 1 \%$ and $1.2 \%$ are added to titanium-gypsum slag cementitious materials. So triethanolamine should not be used as the activator alone.

(3) When $\mathrm{Na}_{2} \mathrm{SiO}_{3}$ mixed with triethanolamine were used as alkaline activator, the 7-day compressive strength of $\mathrm{Na}_{2} \mathrm{SiO}_{3}$ mixed with triethanolamine is generally higher than that of $\mathrm{Na}_{2} \mathrm{SiO}_{3}$ alone, especially when the activator content is $1.2 \%$, when the 7-day compressive strength is the highest.

[8] Test Methods of Materials Stabilized with Inorganic Binders for Highway Engineering. JTG E51-2009, China Profession Standard.

[9] Tao, M. and Zhang, Z. 2005. Enhanced Performance of Stabilized By-Product Gypsum[J]. Journal of Materials in Civil Engineering, 17:617-623.

[10] Hua M, Wang B, Chen L, et al. 2010. Verification of lime and water glass stabilized FGD gypsum as road subbase[J]. Fuel, 89(8):1812-1817.

[11] Zhiqing Li, Xin Shen. 2019. Experimental Study on Sodium Silicate Improved Cement-based Stable Phosphogypsum in Pavement Base Course [J]. Journal of Engineering Geology, 27 (01): 83-90.

[12] Tao, M. and Zhang, Z. 2005. Enhanced Performance of Stabilized By-Product Gypsum[J]. Journal of Materials in Civil Engineering, 17:617-623.

[13] D.-Y. Lei et al. 2017.Study on properties of untreated FGD gypsum-based high-strength building materials[J]. Construction and Building Materials, 153:765-773.

[14] Fan 1 y. 2010. Development of desulfurized gypsumbased steel slag cementitious material [D]. University of Jinan.

[15] Yan-Rong Z, Xiang-Ming K, Zi-Chen L, et al. 2016. Influence of triethanolamine on the hydration product of portlandite in cement paste and the mechanism[J]. Cement and Concrete Research, 87:64-76.

[16] Miaomiao H, Jintang G, Yang X, et al. 2018. Influence of triethanolamine on reactivity of hydrated matrix in $\mathrm{Na} 2 \mathrm{SiO} 3$ self-healing system and the mechanism[J]. Construction and Building Materials, 185:445-452. 